Witold Lenart and Wojciech Nowicki

\title{
SNOW COVER AS A MEDIUM TO STUDY SUPPLY OF POLLUTION FROM THE ATMOSPHERE TO SOIL
}

The presented material constitutes a part of works conducted by the Mazovian Geographic Observatory of the Department of Geography and Regional Studies of Warsaw University concerning dynamics of environment transformations in the zone of action of Poland's largest Refinery and Petrochemical Plant situated in Plock.

The work had an experimental character, and its purpose was to diagnose spatial structure of influence of such a type of plant on the surrounding area.

Efforts were made to analyse all the elements of the natural environment in order to obtain data for spatial balance of anthropogenic matter. In the case of an industrial plant with numerous and differentiated emittors, it is specially important to determine total values of supply of pollution from the atmosphere to the bedding with various location of the site in relation to the Plant. Direct measurement is extremely difficult. Therefore, an indirect method was proposed which was based on the spatial analysis of chemism of snow cover.

The examination of chemism of snow cover was conducted in the period 1978-1982 and due to improved methodology interesting results were obtained ${ }^{1}$. Results of the experiment from the winter of 1981, which are presented below, proved most interesting.

The examination covered the area located in the vicinity of the Mazovian Refinery and Petrochemical Plant and the town of Plock of the total acreage of $400 \mathrm{sq} \mathrm{km}$. From that area 163 snow samples were collected as simultaneously as possible (within 2-3 days) and they were experimentally analysed. In the samples first of all $\mathrm{SO}_{4}^{-}, \mathrm{Cl}^{-}, \mathrm{HCO}_{3}^{-}$, $\mathrm{CO}_{3}^{--}, \mathrm{Ca}^{+}, \mathrm{Na}^{+}, \mathrm{Mg}^{++}, \mathrm{pH}$ were determined, and in some samples collected earlier, additionally content of vanadium, cadmium and copp-

1 These investigations were first arganized by $\mathrm{dr} B$. Wicik and his team 0 f the Department of Geography and Regional Studies, Warsaw University.

7 Miscellanea Geographica 


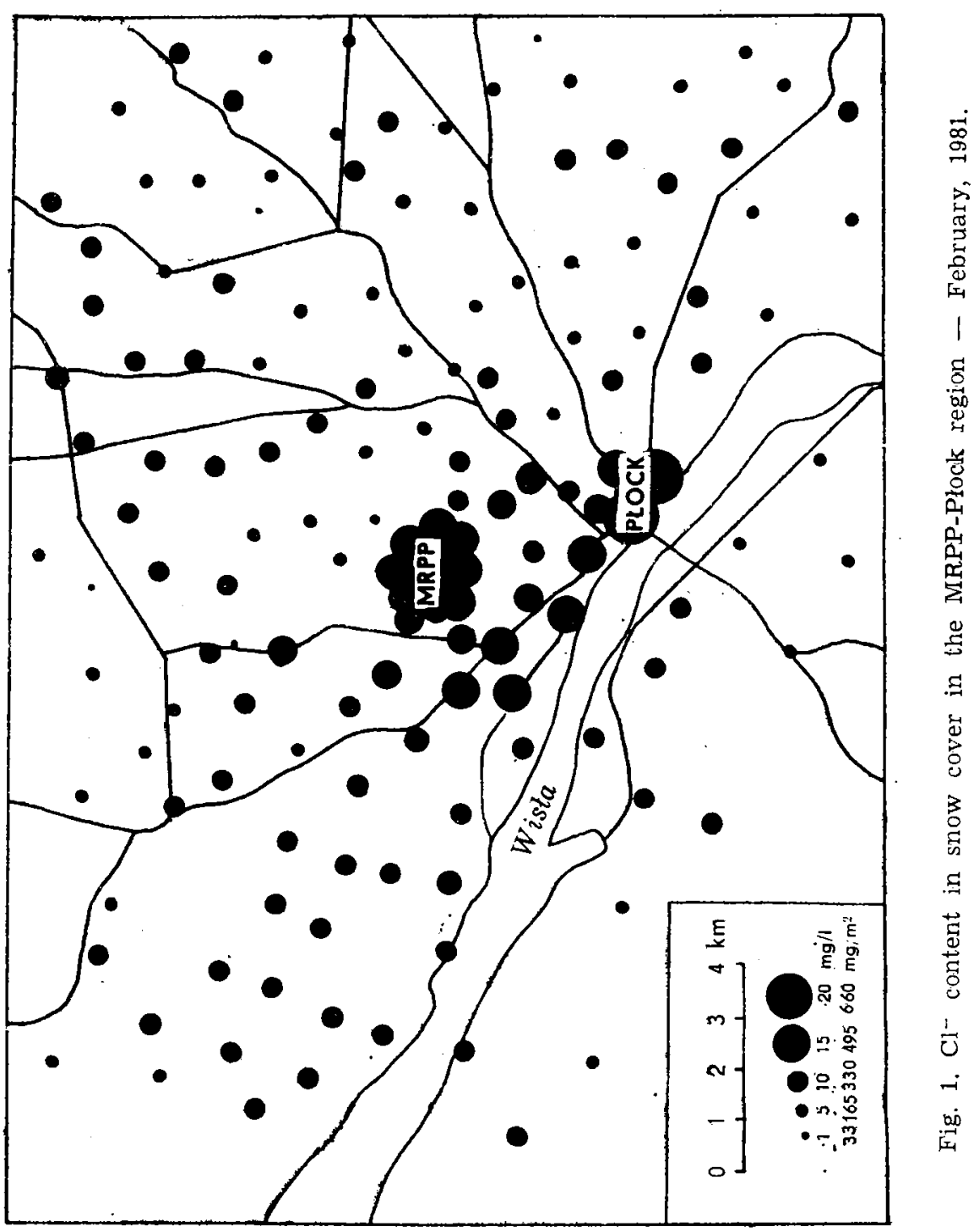


er, zinc, as well as nickel was fixed. Furthermore, in about 30 places collection of samples was repeated after one week and they were subjected to the above-mentioned analyses.

Efforts were made to choose the places to collect the studies with the exception of the sites situated in the immediate vicinity of the Plant and the town where the collection net was to some extent thickened.

The results of laboratory analyses were tabulated and after a simple statistical arrangement they were presented in a graphic form. The material prepared in this way together with the accompanying study of meteorological conditions was used to analyse the range of expansion of the examined chemical substances.

Taking into account the assumptions made by the research team, to define the date of starting the examination was a very significant element. The issue was to make use of such a meteorological situation when short but strong warmer weather would melt the whole snow cover so that later on, in the period of coolness, forming of a fresh snow cover could be observed with full knowledge of the characteristics of the accompanying meteorological conditions. Such a situation occurred at the end of the first decade of February, 1981, and on 11th February, 1981 at 4.05 a.m. first snow fall was noted. Having waited till 23rd February, 1981, and having ascertained that the snow cover was appropriately shaped, we collected samples from the places earlier selected on the basis of cartographic materials and taking into account results from previous years.

The samples were collected from places of possibly the same height of snow layer (about $15 \mathrm{~cm}$ ), from a precisely determined and measured area and with possibly homogeneous water equivalent of snow. Water equivalent of snow is a parameter defining water content in snow cover and it is expressed in millimetres of water per $1 \mathrm{~cm}$ of height of snow cover, or simpler it is the height of water layer obtained after melting snow $1 \mathrm{~cm}$ high.

Finding snow of precisely the same water equivalent is practically very difficult and demands much effort. Due to that a tolerance limit of 2.1-2.3 was accepted in this methodology. Therefore, assuming the height of snow layer of $15 \mathrm{~cm}$, water content in $1 \mathrm{~m}^{3}$ of the cover showed the following variations:

- water equivalent of snow $2.1 \mathrm{~mm}-31.5 \mathrm{dm}^{3}$ of water in $1 \mathrm{~m}^{2}$ of snow cover $15 \mathrm{~cm}$ high.

- water equivalent of snow $2.2 \mathrm{~mm}-33.0 \mathrm{dm}^{3}$ of water in $1 \mathrm{~m}^{2}$ of snow cover $15 \mathrm{~cm}$ high. 


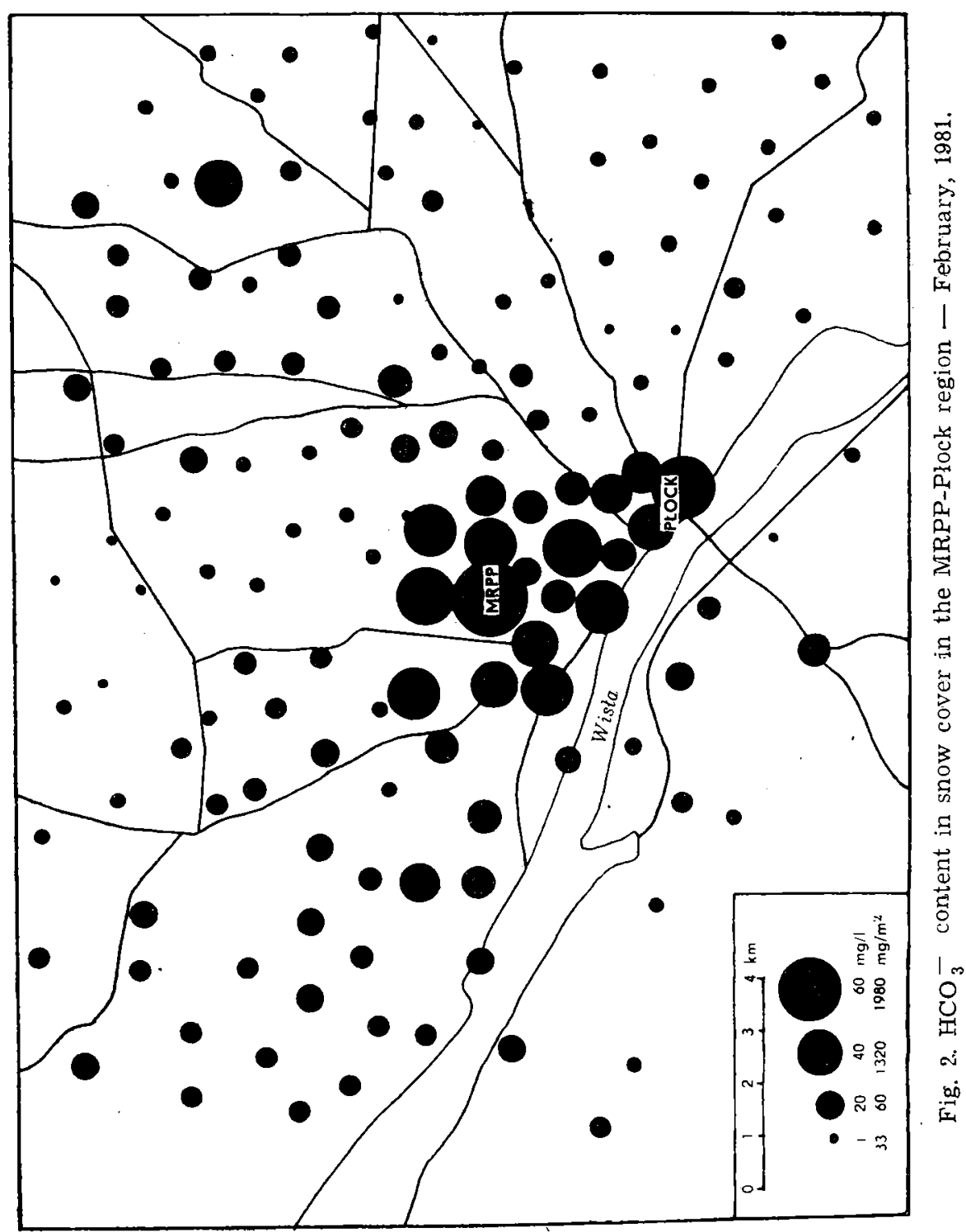


- water equivalent of snow $2.3 \mathrm{~mm}-34.5 \mathrm{dm}^{3}$ of water in $\mathrm{m}^{2}$ of snow cover $15 \mathrm{~cm}$ high.

Due to adoption of methodology which took into account similar height of snow layer, similar water equivalent of snow as well as making of precise measurement of the sampling area, a very important feature was obtained, namely, the samples were collected from places characterized by relative homogeneity with reference to water content in relation to layer thickness, quality of snow and its surface. This allows one to some extent to pass on from laboratory calculations $\mathrm{mg} / \mathrm{l}$ to comparable calculations referring to $1 \mathrm{~m}^{2}$ of snow cover area since water content in each metre of the cover undergoes only slight variations. The variations do not influence much the substantial value of the obtained spatial picture.

The error consisting in the fact that it is impossible to sample all the snow (the residue remains in the ups and downs of the soil) cannot be avoided but one should be aware that this concerns in principle collecting of each sample, therefore this has not big importance for spatial interpretation.

During the collecting, the snow was packed in chemically clean plastic bags and after collecting the whole series, it was transported to the Mazovian Geographic Observatory of the Department of Geography and Regional Studies of Warsaw University at Murzynowo in the vicinity of Płock.

Chemical analyses of the snow samples were made using an atomic spectrophotometer. About 2,000 unit analyses were made on the collected samples.

The results of the laboratory analyses denominated in $\mathrm{mg} / \mathrm{l}$ were converted in such a way that content of individual chemical elements in water coming from $1 \mathrm{~m}^{2}$ of snow cover was obtained.

Spatial interpretation of the obtained results was made against a background of a topograhical map on the scale of $1: 50000$. Individual values of concentration were presented in the form of circles whose diameter defines the value according to the explanations included in each map.

When the snow cover studied by the research team began to take shape (11th February, 1981), all the indispensable information considered necessary to be used in this paper, was begun to be collected. The information concerned:

- meteorological phenomena registered non-stop and covering the time of their duration (special attention was paid to precipitation), 
- direction of wind registered every hour (according to a sixteen-direction wind rose),

- velocity of wind registered every hour,

- average daily temperature of air,

- daily maximum temperature,

- values of water equivalent of snow,

- height of snow cover,

- height of freshly fallen snow,

- values of snow evaporation.

The above information was obtained from a synoptic station of the Institute of Meteorology and Water Economy in Płock-Trzepowo, as well as from meteorological testing grounds of the Observatory.

The data concerning direction and velocity of wind was statistically arranged (share of wind in per cent in relation to the direction and velocity) and presented in a graphic from (an eight-direction wind rose).

The four maps attached to the paper present spatial distribution of concentration of chlorides, acid carbonates, sulphates as well as generai mineralization of the studied compounds.

The results of chemical analyses of over a hundred snow samples collected in places situated in the area of about $400 \mathrm{sq} \mathrm{km}$ around the Mazovian Refinery and Petrochemical Plant (MRPP) and the town of Plock show clearly that the quantity of the studied chemical substances which was present in the snow water is usually insignificant. Taking into account the overall mineralization of the studied compounds, it was within the range of 130 to $140 \mathrm{mg} / \mathrm{l}$ in the samples collected in the town or in the Plant or in the areas in the immediate vicinity, down to $14-20$ $\mathrm{mg} / \mathrm{l}$ in the snow water collected in places situated considerably far from the Plant (about $6 \mathrm{~km}$ ), especially northwards. Totally for all the collected samples the mean value of mineralization with reference to the studied compounds is about $40 \mathrm{mg} / \mathrm{l}$. When converting this into $1 \mathrm{sq}$ metre of snow cover it is clear that only in very few places the total content of the studied substances exceeds $1,200-1,409 \mathrm{mg} / \mathrm{m}^{2}$.

Apart from the above issue of the value of sedimentation of chemical substances in snow cover, another crucial problem is the question of spatial picture of concentration of individual chemical compounds considered against a background of all factors that have had an impact on its shape. The most important factor here are meteorological conditions that accompanied forming of the snow cover and later on prevailed in the time from its formation until sampling. The most important meteogical parameters which demand precise determination due to their 
importance in transportation of chemical substances in the atmosphere, are in this case the direction and velocity of wind.

The direction of wind in the period of research $(10$ th-25th February, 1981) underwent quite frequent changes, however, with a majority of eastern winds, i.e. share of $\mathrm{NE}$ winds was $24 \%, \mathrm{E}$ winds- $30 \%$, and SE winds-17\%. The directions with least frequent winds were: $\mathrm{S}-2^{0} \%, \mathrm{~N}-5^{\%} \%$ and $\mathrm{W}$ and $\mathrm{NW}-7^{0} \%$ each. The structure of wind directions in various velocity ranges is quite similar. The structure of velocity does not differ much from average conditions for winter, i.e. velocity is much higher than in the warm season of the year.

The clear predominance of eastern winds in the period of studies is a basic explanation for the spatial picture that was obtained analysing individual snow samples. Higher concentration that is observed on the west side of the studied area is a result of translocation in the atmosphere of anthropogenic chemical compounds cumulating over a big industrial plant due to eastern winds. Unfortunately, the discussed direction of wind (especially $\mathrm{SE}$ ) is not favourable to distinguish the influence of the MRPP and the town of Płock as two separate sources of pollution. The chemical substances emitted by the two sources when reaching the snow cover overlap and their origin (Plock or MRPP) is impossible to determine.

Belaw a detailed description of the obtained results is presented which refers to individual chemical substances which were studied in the collected samples together with their spatial interpretation. It is necessary to mention that among the results obtained there were a few (below $2 \%$ ) whose values differ considerably from the results obtained in the reighbouring places. While constructing the spatial picture they were ignored as little reliable. The cause of errors was probably non-observance of strict rigours of the methodology of sampling (e.g. too short distance from a road or buildings).

The highest concentration of sulphates in the examined snow cover exceeding $16 \mathrm{mg} / \mathrm{l}$, and after conversion into $1 \mathrm{~m}^{2}$ of the cover-528 $\mathrm{mg} / \mathrm{m}^{3}$, was observed in three regions covering relatively small areas: the centre of the Plant, its south-western part with the immediate neighbourhood about $1 \mathrm{~km}$ long and the centre of Plock, especially its older part. This is understandable since in the case of the MRPP there are numerous organized and non-organized emissions of $\mathrm{SO}_{2}$ and the occurrence of relatively high concentration outside the western border of the. Plant results from wind blowing and washing out of $\mathrm{SO}_{2}$ from the atmosphere by eastern winds. In the case of Plock, high concentration that is observed in its old part, is a result of coal heating 


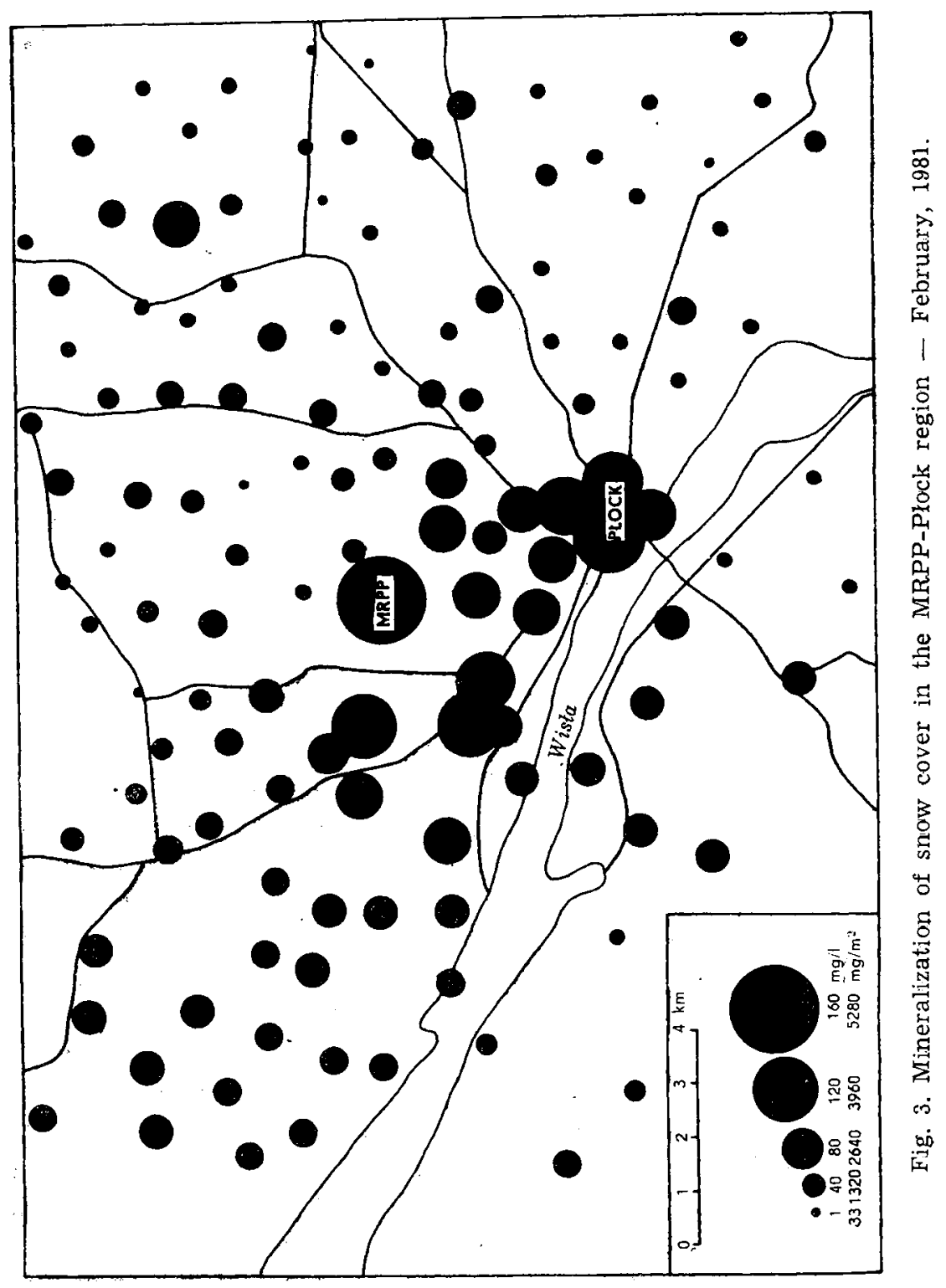


on the one hand and relatively dense road traffic in narrow, tunnel-like streets on the other.

The area around the MRPP-Płock complex covering much larger area is characterized by concentration not lower than $12 \mathrm{mg} / 1\left(396 \mathrm{mg} / \mathrm{m}^{2}\right)$. One part covers the area around the Plant and goes westwards for about three kilcmeters, another covers the whole area of Płock till the Brzeznica River canyon, and another one, smaller, is situated west of the Plant obout $5-7 \mathrm{~km}$ from its limits between the Skriwa Prawa vailey and Ulaszewo and Biskupice. The fact that on the west side there occurs an isolated area with higher concentration than the surrounding area with simultaneous lack of any big immediate source of emission can be explainerd only in the following way: this area lies on the line of prevailing wind direction but is rather far from the MRPP-Plock complex and it is not under the influence of non-organized emission from low emittors of those centres but the impact of emittons form high levels is marked here.

Concentration $8-12 \mathrm{mg} / 1\left(246-396 \mathrm{mg} / \mathrm{m}^{2}\right)$ is characteristic of a big area stretching out west (to the Murzynowo-Siecien line) and south of the MRPP-Plock complex. Its eastern border line runs quite close to the Plant limits and in the vicinity of Trzepawo as well as Plock close to Podolszyce. In the remaining part of the studied area $\mathrm{SO}_{4}^{-}$content is inconsiderable, on the average ranging from 4 to $7 \mathrm{mg} / \mathrm{l}$. Particularly low values are observed in samples collected in the northern part of the area and on its eastern border.

Spatial distribution of other chemical compounds under study gives a similar picture. Only absolute values of concentration are different due to individual specificity of the particular chemical substances and the value of their emission to the atmosphere.

As mentioned in the introduction, the fundamental purpose of the examination of snow was to delimit the zone of influence of the MRPP on the environment. Under precisely defined meteorological conditions the range, identified 'with the range of increased concentration of selected chemical substances, is clearly visible. Therefore, it is possible to try to delimit approximately the aforesaid zone on the basis of meteorological statistics.

The basic issue is to determine representativeness of the results obtained. Dismissing laborious studies, the following can be stated:

(1) The two-week research period is characteristic of:

(a) snowy winter,

(b) influx from the eastern sector, 
(c) velocity of wind higher by about $30 \%$ than usually in Poland.

(2) Although conditions of the spreading of pollution in a dry way and through washing out from the atmosphere during winter and summer differ (different conditions of washing out by rain and different conditions for photochemical processes in the atmosphere), taking into consideration the scale of the study they can be differentiated only by the above-mentioned meteorological parameters.

(3) Cumulation of pollution in the snow cover can be roughly treated as a process dependent on the one hand on supply of polluting substances, and on balance of snow mass on the other.

Roughly speaking, it can be accepted that for the cool season of the year the observed gradients of concentration are characteristic of each direction of influx under average conditions. Since the average distribution of wind directions for the cool season is known for Płock, using proportional frequency of winds for the four main sectors as a balance, the ranges of individual concentrations around the MRPP can be determined. During the calculation, it is also necessary to make the balance of snow mass and particularly to take into consideration diminution of thickness of the cover due to evaporation. The value of snow evaporation for that period is approximately $8-10 \mathrm{~mm}$, which makes it necessary to reduce the results by $15-20 \%$. Mean values for particular sectors and periods in the cool season of the year would be similar to the ones obtained in the two-week study decreased as follows:

- for areas east of MRPP by $60 \%$

- for areas north of MRPP by $90 \%$

- for areas south of MRPP by $80 \%$

- for areas west of MRPP by $70 \%$.

For the warm season of the year a similar analysis should take into consideration difference in wind velocity (values of concentration will be somewhat higher).

Summing up it can be said:

(1) The method of studies of chemism of snow cover is convenient to study spatial influence of the MRPP on the natural environment.

(2) Results obtained in 1981 and in preivous years show that mean values of concentration of the studied chemical substances for a couple of weeks' periods are rather low and only in the immediate vicinity of the Plant and Plock do they reach the level characteristic of highly industrialized regions.

(3) Distribution of concentrations is clearly connected with the two 
equivalent centres - the MRPP and Plock, and it is decidedly dependent on the direction of influx of air masses.

(4) Values of background to the windward range between 40 and $50 \%$ of mean values for the studied region.

(5) Analysis of content of heavy metals confirms the previous observations on increased concentration of vanadium and cadmium in the immediate vicinity of the MRPP.

(6) The applied methodology allaws one to obtain mean values of concentration for the environs of the MRPP.

(7) The obtained cartographic picture reveals two clearly concentric zones of increased concentration: the closer one, up to $2 \mathrm{~km}-$ connected with non organized emission and low emittors, and the farther one - connected with the emission from high levels.

(8) In our opinion, the most significant needs connected with realization of the discussed research task cover the following:

(a) extension of the list of the studied chemical compounds by those which are closely connected with the technological processes of the Plant;

(b) continuation and extension of studies on spatial distribution of pollution under conditions inconvenient to its spreading;

(c) studies on further stages of pollution migration;

(d) final determination of origin of some groups of pollution of which the increased concentration is absolutely confirmed.

\section{BIBLIOGRAPHY}

A ndersson, T., "Small-scale Variations of the Contamination of Rain Caused by Washout from the Low Layers of the Atmosphere". Tellus 21, 1967.

Chemistry of the Lower Atmosphere (ed.) S. I. Rasol. Plenum Press, London 1973. D ę bowski, A., Rozklad siarczanów jako jednego ze sktadników zanieczyszczenia przemystowego środowiska wodno-gruntowego (Distribution of Sulphates as One of the Elements of Industrial Pollution of the Water-soil Environment), Materials of the 3rd Symposium of the Chief Technical Organization "Protection and Shaping of the Natural Environment", Płock 1982.

Lenart, W., "Osobliwości cyrkulacji lokalnej w okolicy Płocka" (Pecularities of Local Circulation around Płock), Notatki Plockie No. 1, 1977.

Mol1er, U., Schumann, G., "Mechanisms of transport from the atmosphere to the Earth's surface", J. Geophys. Res. 75, 1970. 
